\title{
PENGEMBANGAN PARIWISATA KONSERVASI SAVANA PROPOK, LOMBOK, NUSA TENGGARA BARAT
}

\author{
I Komang Deya Pradnyana \\ Program Studi Magister Pariwisata Universitas Udayana \\ Email: deya.pradnyana@gmail.com \\ Agung Suryawan Wiranatha \\ Pusat Unggulan Pariwisata Universitas Udayana \\ Email: agung_suryawan@unud.ac.id \\ I Gusti Ayu Oka Suryawardani \\ Program Studi Magister Pariwisata Universitas Udayana \\ Email: gungdani@gmail.com
}

\begin{abstract}
This research was conducted to design a conservation-based tourism development strategy in Savana Propok Sembalun, Lombok, West Nusa Tenggara. In developing Savana Propok Sembalun as conservation-based tourism, a general strategy (grand strategy) and alternative strategies are needed to develop all the existing potential, and support its development into a conservation tourism attraction that can benefit all parties, especially for the local community, so it is necessary to conduct research on (Conservation-Based Tourism) Savana Development Strategy in Propok Sembalun, Lombok, West Nusa Tenggara. This study was designed using a qualitative approach with the EFAS, IFAS, and SWOT matrix analysis methods. The data in this study were obtained through direct field observations and in-depth interviews with related parties. The results of this study refer to the internal and external environmental conditions of Savana Propok Sembalun, each of which are in a averange condition. Thus, the right alternative strategy to be applied at the next stage of development is to hold and maintain without changing the direction of the strategy that has been used. This alternative strategy emphasizes more on (1) Tourism Development Strategy, (2) Conservation Tourism Planning Strategy, (3) Conservation-Based Tourism Development Strategy, (4) Environmental Quality Improvement Strategy, (5) Human Resource Development Strategy, and (6) Tourist Attraction Promotion Strategy.
\end{abstract}

Keywords: Development Strategy, Tourism, Conservation. 


\section{Pendahuluan}

Berkembangnya sektor pariwisata di suatu negara akan menarik sektor lain untuk berkembang pula karena produk-produknya diperlukan untuk menunjang industri pariwisata, seperti sektor pertanian, peternakan, perkebunan, kerajinan rakyat, peningkatan kesempatan kerja, dan lain sebagainya. Dengan adanya keterkaitan antara sektor industri pariwisata dengan sektor-sektor lainnya, diharapkan mampu menghasilkan devisa dan dapat pula untuk menyerap tenaga kerja sehingga dampaknya mengurangi angka pengangguran dan meningkatkan tingkat kesejahteraan masyarakat.

Menurut Undang - Undang Nomor 10 Tahun 2009 yang menyatakan bahwa pembangunan kepariwisataan dilakukan berdasarkan asas manfaat, kekeluargaan, adil dan merata, keseimbangan, kemandirian, pelestarian, partisipatif, berkelanjutan, demokratis, kesetaraan, dan kesatuan yang diwujudkan melalui pelaksanaan rencana pembangunan kepariwisataan dengan memperhatikan keanekaragaman, keunikan, dan kekhasan budaya dan alam, serta kebutuhan manusia untuk berwisata. Dalam perkembangan pariwisata Lombok, Pemerintah Provinsi NTB mengeluarkan program pariwisata alternatif yang berlandaskan pada konservasi lingkungan, social, budaya, dan peningkatan ekonomi lokal (www.ntbprov.go.id). Hal ini didasari akibat pariwisata massal yang memberikan pengaruh cukup signifikan terhadap perubahan iklim global, degradasi social-budaya, kerusakan ekosistem, dan kesenjangan sosial. Dampak negatif pariwisata diharap dapat diminimalkan melalui adanya pariwisata alternatif. (Haywood, 1988; Murphy, 1985).

Sejumlah persoalan lingkungan di kawasan TNGR termasuk Savana Propok Sembalun belum dapat diatasi. Berdasarkan kajian ekologi WWF-NT (2008) mengungkapkan bahwa selama periode tahun 1997-2006 terjadi penurunan luas tutupan hutan primer kawasan Gunung Rinjani 4,57\% per tahun. Daerah Aliran Sungai (DAS) di kawasan ini rusak dan menunjukkan penurunan debit rata-rata 
sebesar 3,8\% per tahun (Balai TNGR, 2011; Sukardi, 2009; WWF-NT, 2008). Kerusakan biofisik ini disebabkan oleh perambahan hutan, penebangan liar (Balai TNGR, 2011; Dipokusumo, 2011), pembuatan arang, pengambilan kayu bakar dan perburuan satwa (Balai TNGR, 2011), pelanggaran awig- awig (aturan main yang dibangun bersama oleh para pihak yang terlibat pengelolaan sumber daya alam), kurangnya kapasitas kelembagaan dan lembaga adat, kurangnya kebijakan yang memadai (Dipokusumo, 2011). Participatory Action Research (PAR) Rinjani tahun 2002 secara multipihak mengungkapkan bahwa permasalahan sosial ekonomi dan kerusakan lingkungan kawasan TNGR berakar pada kurangnya perhatian kebijakan pada persoalan sosial budaya, ekonomi, rendahnya pemahaman dan kesadaran tentang pengelolaan sumber daya alam berkelanjutan dan ekowisata, lemahnya kelembagaan sosial, memudarnya tata nilai lokal dan permasalahan kelembagaan lainnya (Rai, 2010). Tingkat kesejahteraan ekonomi masyarakat kawasan TNGR relatif rendah, sekitar 70\% dari 600 ribu jiwa penduduk termasuk kategori miskin (Markum, Sutedjo, \& Hakim, 2004; Scheyvens, 2007; Sukardi, 2009). Bahkan, kawasan TNGR rawan konflik lahan dan pembukaan hutan (Baharuddin, 2009; Sukardi, 2009).

Pengembangan Savana Propok Sembalun sebagai daya tarik pariwisata berbasis konservasi dimaksud agar kegiatan pariwisata di daerah tersebut dapat berkelanjutan dari aspek ekonomi, sosial budaya, dan lingkungan. Sehingga nantinya dampak negatif yang timbul dari kegiatan pariwisata dapat diminimalisir. Selain itu terjadinya perusakan dan pencemaran lingkungan juga masih saja terjadi di lingkungan Kawasan Gunung Rinjani termasuk Daya Tarik Wisata Savana Propok Sembalun juga belum mendapatkan perhatian kusus dari pihak pemerintah ataupun pengelola setempat mengenai pengembangan di Savana Propok Sembalun sebagai upaya menjaga kelestarian lingkungan.

Meskipun Daya Tarik Wisata Savana Propok Sembalun masih tergolong baru dan alami, namun kondisi fasilitas pendukung seperti toilet umum, papan penunjuk jalan, camping ground, tempat pembuangan sampah masih minim. Berbeda dengan 
destinasi yang berada di Kabupaten Lombok Utara yang sudah maju, saat ini kepariwisataan di Savana Propok Sembalun masih belum berkembang, perlu diadakannya strategi pengembangan Daya Tarik Wisata guna mendukung kegiatan pariwista berbasis konservasi. Dalam Pengembangan Savana Propok Sembalun sebagai pariwisata berbasis konservasi diperlukan strategi umum (grand strategy) maupun alternatif strategi guna mengembangkan segala potensi yang ada, dan mendukung pengembangannya menjadi daya tarik wisata konservasi yang dapat menguntungkan semua pihak terlebih bagi masyarakat setempat, sehingga perlu diadakan penelitian mengenai (Pariwisata Berbasis Konservasi) Strategi Pengambangan Savana Propok Sembalun, Lombok, Nusa Tenggara Barat.

\section{Landasan Teori dan Kajian Pustaka}

Model pembangunan ekowisata biasa disandingkan dengan model pembangunan kepariwisataan bertanggungjawab (responsible tourism). Tujuan dari kepariwisataan bertanggungjawab adalah kondisi pengembangan kepariwisataan yang berusaha untuk meminimalkan dampak negatif terhadap lingkungan dan masyarakat (Sunaryo, 2013). Model pengembangan kepariwisataan bertanggungjawab ini lebih ditekankan pada kesadaran wisatawan saat melakukan perjalanan, yakni perilaku kunjungan wisatawan di suatu DTW (Sunaryo, 2013).

Prinsip-prinsip dasar yang dikemukakan oleh (Sunaryo, 2013) untuk memperjuangkan model pengembangan kepariwisataan bertanggung jawab adalah (1) mendorong keuntungan ekonomi untuk masyarakat lokal dan mempertinggi ketahanan kearifan lokal, membuka akses masyarakat kepada usaha industri pariwisata; (2) melibatkan masyarakat lokal dalam pengambilan keputusan dibidang kepariwisataan disekitarnya yang dapat mempengaruhi kehidupan mereka; (3) menumbuhkan kontribusi positif untuk konservasi SDA dan cultural heritage untuk memperkaya keragaman yang ada; (4) menyediakan pengalaman kunjungan wisatawan yang lebih bernilai dalam hubungannya dengan masyarakat lokal, 
kearifan lokal, isu-isu sosial dan lingkungan setempat; (5) meminimalisir dampak negatif ekonomi, lingkungan, budaya dan sosial dari kegiatan kepariwisataan; serta (6) menumbuhkan saling menaruh respek antara wisatawan dengan tuan rumah, dan membangun kebanggaan lokal serta percaya diri dari masyarakat.

Tinjauan hasil penelitian sebelumnya yang dimaksud adalah kajian hasil karya tulis yang berhubungan dengan penelitian ini, khususnya yang dengan pengembangan kawasan. Hasil-hasil dari penelitian tersebut akan di uraikan secara singkat yang selanjutnya hasil dari penjelasan tersebut akan dijadikan pedoman untuk penelitian ini.

\section{Metode Penelitian}

Pendekatan penelitian yang digunakan adalah pendekatan penelitian kualitatif. Penelitian kualitatif adalah penelitian yang menghasilkan data deskriptif berupa kata-kata tertulis atau lisan dari narasumber atau perilaku yang diamati untuk mendapatkan semua fakta yang terkait. Metode penelitian ini berlandaskan pada instrumen kunci penelitian kualitatif yaitu peneliti itu sendiri. Penelitian ini dilakukan pada objek yang dikembangkan oleh sekelompok pengelola, dimana data objek yang diperoleh tidak dimanipulasi oleh peneliti dan kehadiran peneliti tidak mempengaruhi jika pada objek yang diteliti.

Sebagaimana disebutkan di atas, dalam penelitian ini, Peneliti menggunakan beberapa jenis analisis kuaitatif yaitu (1) observasi terlibat, di mana Peneliti melibatkan diri dengan para pengambil kebijakan dan pelaksana kebijakan mengenai perspektif mereka terhadap pengembangan Savana Propok Sembalun, Lombok, Nusa Tenggara Barat, (2) analisis percakapan, di mana Peneliti mengolah hasil wawancara dengan para nara sumber, (3) analisis wacana, di mana Peneliti melihat pelaksanaan berbagai jenis wisata Savana Propok Sembalun, Lombok, Nusa Tenggara Barat guna membangun sebuah strategi pengembangan, (4) analisis isi, di mana Peneliti 
menggali berbagai dokumen tentang wisata Savana Propok Sembalun, Lombok, Nusa Tenggara Barat, dan (5) pengambilan data etnografis.

\section{Hasil dan Pembahasan}

Menurut (Balai Taman Nasional Gunung Rinjani, 2020) Savana Propok Sembalun memiliki hamparan padang savanna yang luas dan indah dengan keragaman flora dan fauna. Kekayaan flora yang dimiliki kawasan taman nasional ini menjadi salah satu daya tarik utamanya. Jenis-jenis flora yang ditemukan pun beragam dan mengikuti alur ketinggian. Flora yang tumbuh di kawasan Taman Nasional Gunung Rinjani dapat dibagi menjadi tiga berdasarkan ketinggian gunung. Ketiga jenis tersebut adalah daerah dengan ketinggian di bawah 1.000 meter di atas permukaan laut, di atas 1.000 meter di atas permukaan laut, dan puncak gunung.

Faktor utama yang dapat menjadi potensi dalam pengembangan suatu daerah atau pulau menjadi sebuah destinasi pariwisata adalah harus memiliki potensi wisata yang bisa dijadikan daya tarik wisata, baik itu berupa kekuatan maupun peluang yang dapat mendukung pengembangannya. Potensi yang dimaksud adalah bentang alam suatu daerah, misalnya perbukitan, hutan, padang savanna, dan lain-lain (keadaan fisik suatu daerah). Kelebihan dan keunikan yang dimiliki oleh alam jika dikembangkan dengan memperhatikan keadaan lingkungan sekitarnya niscaya akan menarik wisatawan untuk berkunjung ke daya tarik wisata. Sebagai kawasan yang terlindungi, Savana Propok Sembalun tidak hanya memiliki pesona alam yang memikat. Melainkan juga kaya akan berbagai jenis flora dan fauna. Sepanjang jalur pendakian, mata kita akan disuguhi berbagai jenis keanekaragaman hayati. Bahkan tidak jarang ditemukan flora dan fauna langka.

Berdasarkan kekuatan dan kelemahan dalam pengembangan pariwisata berbasis konservasi di Savana Propok Sembalun, maka melalui matriks SWOT akan ditemukan beberapa strategi pengembangan yang dapat mendukung kelayakan 
pengembangan pariwisata berbasis konservasi di Savana Propok Sembalun. Dalam analisis SWOT yang disajikan, disusun beberapa alternatif pengembangan pariwisata berbasis konservasi di Savana Propok Sembalun sebagai strategi khusus, yang merupakan opsi-opsi pengembangan dari grand strategy. Beberapa alternatif yang disusun yaitu; (1) Strategi Pengembangan Daya Tarik Wisata, (2) Strategi Perencanaan Pariwisata Konservasi, (3) Strategi Penetrasi Pasar (4) Strategi Pengembangan Pariwisata Berbasis Konservasi, (5) Strategi Promosi Daya Tarik Wisata (6) Strategi Peningkatan Kualitas Lingkungan, dan (7) Strategi Pengembangan Sumber Daya Manusia. Setiap strategi yang digunakan dalam pengembangan pariwisata berbasis konservasi di Savana Propok Sembalun dapat diuraikan sebagai berikut:

Tabel 1. Analisis Matriks SWOT Savana Propok Sembalun

\begin{tabular}{|c|c|c|}
\hline IFAS & $\begin{array}{l}\text { KEKUATAN (Strengths) } \\
\text { - Keindahan Alam } \\
\text { - Panorama Untuk Fotografi } \\
\text { - Ragam Sumber Daya } \\
\text { Alam Hayati } \\
\text { - Sumber Mata Air } \\
\text { - Area Pantau Savana } \\
\text { - Camping Ground } \\
\text { Savana Propok } \\
\text { Sembalun } \\
\text { - Keramahan Masyarakat } \\
\text { Sekitar }\end{array}$ & $\begin{array}{l}\text { KELEMAHAN } \\
\text { (Weakneses) } \\
\text { - Jarinagan Listrik } \\
\text { - Kebersihan Lingkungan } \\
\text { - Papan Informasi } \\
\text { - Fasilitas Toilet } \\
\text { - SDM Pariwisata }\end{array}$ \\
\hline $\begin{array}{l}\text { - Kawasan Konservasi } \\
\text { - Kemajuan Teknologi } \\
\text { Informasi \& }\end{array}$ & $\begin{array}{l}\text { STRATEGI S-O } \\
\text { 1. Strategi Pengembangan Daya } \\
\text { Tarik Wisata } \\
\text { 2. Strategi Perencanaan } \\
\text { Pariwisata Konservasi } \\
\text { 3. Strategi Penetrasi Pasar }\end{array}$ & $\begin{array}{l}\text { STRATEGI W-O } \\
\text { 1. Strategi Pengembangan } \\
\text { Pariwisata Berbasis } \\
\text { Konservasi }\end{array}$ \\
\hline
\end{tabular}




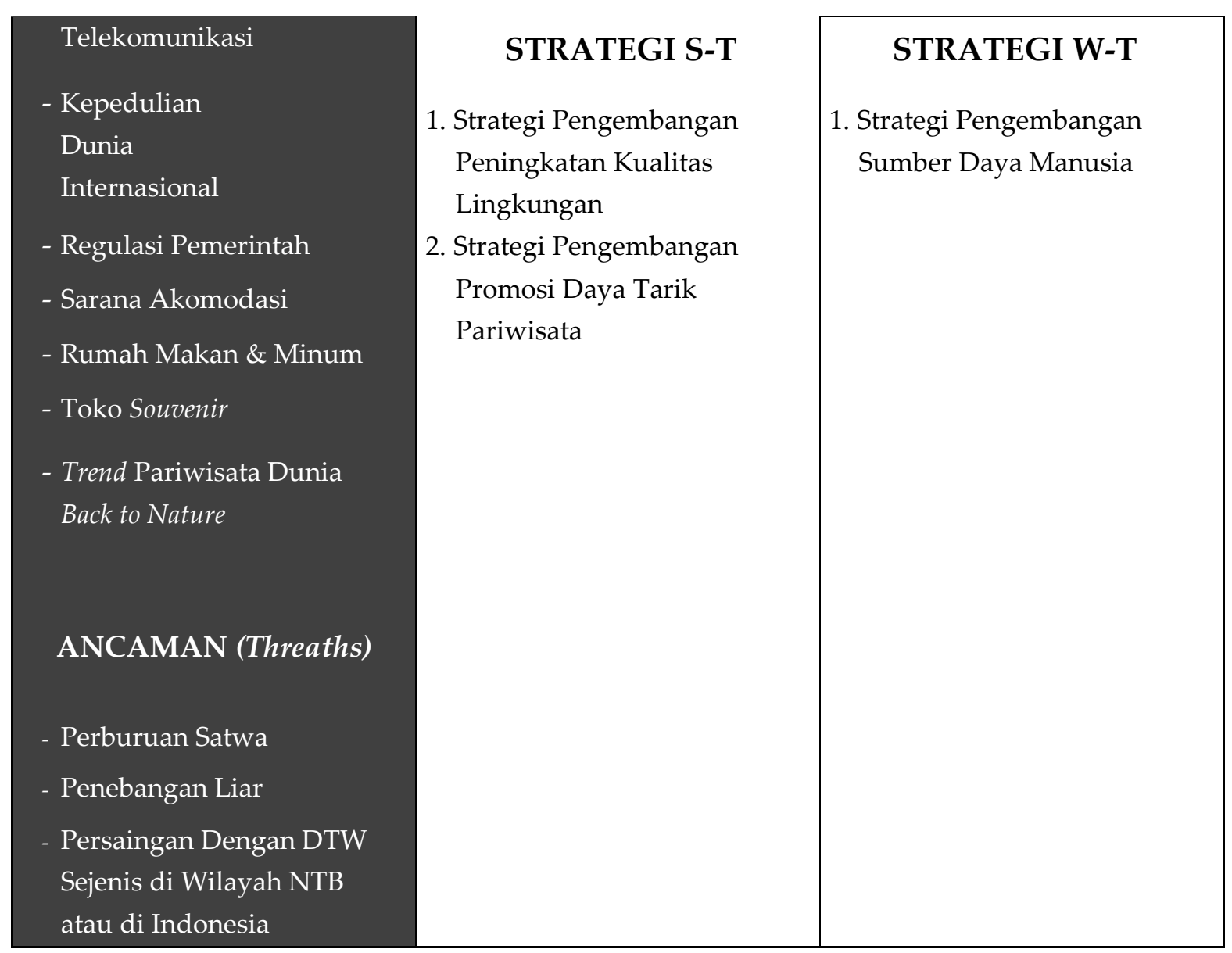

Sumber: Peneliti, 2021

Berdasarkan matriks analisis SWOT maka dihasilkan strategi sebagai berikut:

\section{Strategi Strength-Opportunity (S-O)}

Strategi strength-opportunity merupakan strategi yang menggunakan kekuatan untuk memanfaatkan peluang, sehingga menghasilakan strategi pengembangan daya tarik wisata dan strategi perencanaan pariwisata konservasi. Kekuatan yang dimilikinya harus digunakan dengan semaksimal mungkin agar dapat memanfaatkan segala peluang yang ada dengan sebaik-baiknya. Strategi pengembangan daya tarik wisata. Pengembangan daya tarik wisata sangat perlu dilakukan untuk mendukung pengembangan pariwisata berbasis koservasi di Savana Propok Sembalun. Salah satu langkah yang dapat diterapkan dalam pengembangan daya tarik wisata yaitu pengembangan produk wisata. Suatu daya tarik wisata akan berkembang dengan baik jika tetap menjaga dan mengembangkan produk wisata. 
Program pengembangan produk wisata sangat perlu untuk memperhatikan aspek kekhasanya, keunikan, keaslian dan juga kualitasnya sehingga dapat memicu motivasi dan ketertarikan wisatawan untuk membeli produk wisata yang dikembangkan tersebut, dan berikut adalah penjabaran program pengembangan daya tarik wisata di Savana Propok Sembalun.

\section{Strategi Strength-Threat (S-T)}

Strategi strength-threat merupakan strategi yang menggunakan kekuatan untuk mengatasi ancaman, dimana strategi yang dihasilkan dalam penelitian ini adalah strategi pengembangan peningkatan kualitas lingkungan dan strategi pengembangan promosi daya tarik wisata. Untuk meningkatkan kesadaran masyarakat dalam menjaga kebersihan dan kelestarian lingkungan maka, perlu adanya upaya untuk membangun pola fikir serta budaya wisatawan serta masyarakat yang ramah lingkungan yang dapat dilakukan melalui tindakan pengawasan ataupun aturan yang jelas, pembinaan dan pengelolaan lingkungan hidup baik dari unsur pemerintah, masyarakat, stakeholder maupun para pelaku pariwisata khususnya yang ada di Savana Propok Sembalun untuk menjadikan Savana Propok Sembalun sebagai daya tarik wisata berbasis konservasi maka strategi ini sangat diperlukan untuk mendukung pengembangan tersebut. Untuk meningkatkan pengembangan promosi daya tarik wisata Savana Propok Sembalun, pengelola dapat melakukannya dengan cara memperkenalkan potensi yang ada seperti ragam sumber daya alam hayati, keramahan masyarakat sekitar, kualitas panorama untuk fotografi, sumber mata air, serta area pantau yang dapat menjangkau keseluruhan pemandangan di area Savana Propok Sembalun melalui media social atau mengikuti event-event penting serta festival-festival lainnya serta aktif mengikuti pameranpameran pariwisata. 


\section{Strategi Weakness-Opportunity (W-O)}

Upaya untuk meminimalkan kelemahan untuk memanfaatkan peluang merupakan strategi yang sangat penting digunakan dalam pengembangan sebuah daya tarik wisata. Sehingga strategi yang ditemukan dalam penelitian ini adalah strategi pengembangan pariwisata berbasis konservasi. Pengembangan pariwisata berbasis konservasi merupakan pengembangan pariwisata yang sangat diharapkan pengembangannya baik itu oleh pemerintah, para pelaku wisata (stakeholder) maupun masyarakat itu sendiri, sebab pariwisata berbasis konservasi adalah pariwisata ramah lingkungan dan dapat dinikmati oleh generasi yang akan datang serta memberi perlindungan, pembatasan, serta pemeliharaan kepada suatu area atau lingkungan yang bernilai agar menghindari kemungkinan terjadinya kerusakan apalagi kepunahan pada komponen yang menjadi pembentuk dari lingkungan tersebut, sehingga bisa menyebabkan ketidakseimbangan ekosistem. Adapun manfaat dari upaya pengembangan pariwisata berbasis konservasi di Savana Propok Sembalun secara umum dapat dibagi menjadi dua, yaitu manfaat yang dirasakan oleh manusia dan manfaat yang dirasakan oleh komponen dalam kawasan yang dilestarikan keberlangsungannya.

\section{Strategi Weakness-Threat (W-T)}

Strategi yang meminimalkan kelemahan dan menghindari ancaman merupakan strategi yang mendukung dalam pengembangan pariwisata berbasis konservasi di Savana Propok Sembalun dan dalam strategi ini menghasilkan strategi pengembangan sumber daya manusia.

\section{Kesimpulan}

Berdasarkan hasil penelitian ini dapat disimpulkan bahwa:

1. Potensi Savana Propok Sembalun sebagai daya tarik wisata berbasis konservasi adalah sangat layak dikembangkan. Dalam penembangan, potensi yang dapat 
dikembangkan dapat dibagi menjadi potensi alam, potensi budaya, dan potensi buatan manusia. Potensi alam yang dimiliki Savana Propok Sembalun terdiri dari keindahan savana dengan hamparan padang rumput yang sangat eksotis serta panorama matahari terbit (sunrise), potensi pemandangan kabut, potensi hutan, serta keanekaragaman flora \& fauna yang dimiliki Savana Propok Sembalun. Potensi budaya masyarakat Sembalun terdapat budaya "watu telu" yang masih dipegang erat oleh masyarakat sekitar, dan Potensi buatan manusia yang terdapat di Savana Propok Sembalun adalah camping ground dan area pantau Savana Propok Sembalun.

2. Faktor lingkungan internal terdiri dari faktor kekuatan dan kelemahan. Adapun faktor kekuatan yang dimiliki Savana Propok Sembalun sebagai berikut: Keindahan alam, Panorama untuk fotografi, ragam sumber daya alam hayati, Sumber mata air, Area pantau savana, Camping ground dan keramahan masyarakat sekitar. Sedangkan faktor kelemahan yang dimiliki Savana Propok Sembalun sebagai berikut: Jaringan listrik, Fasilitas toilet, SDM pariwisata, Kebersihan lingkungan, dan kurangnya papan informasi. Adapun faktor peluang yang dimiliki Savana Propok Sembalun sebagi berikut: Kawasan konservasi, kemajuan teknologi informasi \& telekomunikasi, keperdulian dunia internasional, regulasi pemerintah, sarana akomodasi, rumah makan \& minum, toko souvenir, tren pariwisata dunia back to nature. Sedangkan faktor ancaman yang dimiliki Savana Propok Sembalun sebagai berikut: Perburuan satwa, penebangan hutan secara liar, dan persaingan dengan DTW sejenis..

3. Berdasarkan matriks analisis SWOT kondisi lingkungan Savana Propok Sembalun berada pada sel IV dalam Matriks IE yang termasuk dalam strategi mempertahankan dan memelihara (hold and maintain) yaitu: penetrasi pasar, dan pengembangan produk. Strategi alternatif dalam pengembangan pariwisata berbasis konservasi dihasilkan strategi sebagai berikut : (i) Srategi S-O; Strategi Pengembangan Daya Tarik Wisata, Strategi Perencanaan Pariwisata Konservasi \& 
Strategi Penetrasi Pasar. (ii) Srategi S-T; Strategi Pengembangan Peningkatan Kualitas Lingkungan \& Strategi Pengembangan Promosi Daya Tarik Wisata. (iii) Srategi W-O; Strategi Pengembangan Pariwisata Berbasis Konservasi. (iv) Srategi W-T; Strategi Pengembangan Suber Daya Manusia.

\section{Saran}

Berdasarkan hasil penelitian dan simpulan dalam penelitian ini, terdapat beberapa hal yang perlu dilakukan guna mendukung pengembangan pariwisata berbasis konservasi di Savana Propok Sembalun. Beberapa hal tersebut antaranya sebagai berikut;

1. Disarankan meningkatan sumber daya manusia khususnya di sektor pariwisata, baik kualitas maupun kuantitasnya. Hal tersebut sangat perlu dilakukan untuk meningkatkan kualitas pelayanan serta menunjang pengelolaan (manajemen) daya tarik wisata pariwisata yang baik dan efisien.

2. Disarankan sosialisasi mengenai gerakan sadar wisata serta kampanye tentang kebersihan dan kelestarian lingkungan, hal ini dimaksudkan sebagai upaya untuk meningkatkan kesadaran masyarakat untuk lebih perduli terhadap pentingnya menjaga kebersihan dan kelestarian lingkungan. Gerakan sadar wisata diperlukan untuk meningkatkan pemahaman masyarakat mengenai pariwisata sehingga program sapta pesona dapat terlaksana dengan baik di Savana Propok Sembalun, di mana dalam sapta pesona tersebut terdapat upaya pelestarian lingkungan yaitu dengan tetap menjaga kebersihan dan sebagainya. Mengingat Savana Propok Sembalun memiliki keindahan alam yang eksotis, maka kebersihan dan kelestarian lingkungan mutlak diperlukan. Beberapa hal yang bisa dilakukan untuk tetap menjaga kebersihan dan kelestarian lingkungan tersebut yaitu dengan program bersih lingkungan minimal sekali seminggu dengan melibatkan semua pihak termasuk wisatawan. Penerapan konsep wisata ramah lingkungan juga diperlukan untuk mendukung pengembangan pariwisata berbasis konservasi. 
3. Pengembangan pariwisata berbasis konservasi merupakan pengembangan pariwisata yang sangat diharapkan pengembangannya baik itu oleh pemerintah, para pelaku wisata (stakeholder) maupun masyarakat itu sendiri, sebab pariwisata berbasis konservasi adalah pariwisata ramah lingkungan dan dapat dinikmati oleh generasi yang akan datang serta memberi perlindungan, pembatasan, serta pemeliharaan kepada suatu area atau lingkungan yang bernilai agar menghindari kemungkinan terjadinya kerusakan apalagi kepunahan pada komponen yang menjadi pembentuk dari lingkungan tersebut, sehingga bisa menyebabkan ketidakseimbangan ekosistem.

Mengingat penelitian masih terbatas pada identifikasi, analisis serta mengkaji mengenai potensi dan daya tarik, oleh sebab itu perlu adanya penelitian lanjutan yang lebih detail dan spesifik untuk menyempurnakan hasil penelitian ini. Penelitian lanjutan yang dimaksud adalah penelitian yang masih ada relevansinya dengan penelitian ini yaitu tentang kepariwisataan di Savana Propok Sembalun yang lebih detail dan mendalam. Penelitian lanjutan yang dimaksud adalah terkait analisis kajian perkembangan pariwisata di Savana Propok Sembalun, dampak pariwisata pada aspek ekonomi dan sosial budaya masyarakat Savana Propok Sembalun, analisis dampak lingkungan dari kegiatan kepariwisataan di Savana Propok Sembalun, serta penelitian terkait lainnya.

\section{Ucapan Terima Kasih}

Penulis menyampaikan ucapan terima kasih kepada Ir. A.A.Putu Agung Suryawan Wiranatha, M.Sc., Ph.D, selaku pembimbing I yang telah memberikan arahan dan membimbing peneliti dalam menyelesaikan artikel ilmiah ini. Terima kasih kepada Dr. Ir. I Gst Ayu Suryawardani, M.Mgt., Ph.D, selaku pembimbing II yang telah memberikan masukan dan saran untuk penyempurnaan tulisan ini. Selanjutnya penulis mengucapkan terima kasih kepada keluarga dan semua pihak 
yang telah menyediakan waktu untuk berdiskusi dan membantu dalam menyelesaikan tulisan ini.

\section{Daftar Pustaka}

Baharuddin. (2009). Kajian interaksi masyarakat desa sekitar Taman Nasional Gunung Rinjani Provinsi Nusa Tenggara Barat: Studi kasus di Desa Pengadangan, Desa Loloan dan Desa Sembalun Lawang. (Tesis). Bogor: Institut Pertanian Bogor.

Balai TNGR. 2011. "Rencana pengelolaan Taman Nasional Gunung Rinjani 1998- 2023". (Buku II). Mataram: Balai TNGR.

Balai Taman Nasional Gunung Rinjani. 2020. "Potensi Flora \& Fauna", sumber: https://www.rinjaninationalpark.id (Diakses 25 Januari 2020).

Dipokusumo, B. (2011). Model partisipatif perhutanan sosial menuju pengelolaan hutan berkelanjutan: Kasus pembangunan hutan kemasyarakatan pada kawasan Hutan Lindung di Pulau Lombok. (Disertasi). Bogor: Institut Pertanian Bogor.

Haywood, K, M. (1988). Responsible and Responsive Tourism Planning in The Community Tourism Management 9 (2), 105-108.

Markum, Sutedjo, E.B., \& Hakim, M.R. (2004). "Dinamika hubungan kemiskinan dan pengelolaan sumber daya alam pulau kecil: Kasus Pulau Lombok". Mataram: WWFIndonesia Program Nusa Tenggara.

Murphy, P. E. (1985). Tourism: a Community Approach. New York and London: Methuen. NCIP (National Commission on Indigenous Peoples (2000) Tribal Census as of 2000).

Pemerintah Provinsi NTB, 2010. Peraturan Daerah Provinsi Nusa Tenggara Barat Nomor 3 Tahun 2010. [Online] Available at: https://jdih.ntbprov.go.id/content/perdano-3- tahun-2010 [Accessed 23 Desember 2019].

Pemerintah Republik Indonesia, 2009. Undang-Undang Republik Indonesia Nomor 10 Tahun 2009 Tentang Kepariwisataan, Jakarta: Sekretariat Negara RI.

Rai, T. (2010). Pengelolaan ekowisata di kawasan Gunung Rinjani. Mataram: Rinjani Trek Management Board.

Scheyvens, R. 2007. Ecotourism and gender issues. In J. Higham (Ed.). "Critical issues in ecotourism understanding a complex to tourism phenomenon" (pp 185-214). Oxford:Elsevier Ltd.

Sukardi, L. 2009." Desain model pemberdayaan masyarakat lokal dalam pengelolaan hutan berkelanjutan: Kasus masyarakat sekitar kawasan hutan Taman Nasional

Gunung Rinjani Pulau Lombok". (Disertasi). Bogor: Institut Pertanian Bogor. 
Sunaryo, Bambang. 2013. Kebijakan Pembangunan Destinasi Pariwisata Konsep dan Aplikasinya di Indonesia. Yogyakarta: Gava Media.

WWF-NT. 2008. "Laporan studi analisis hidrologis dan perubahan tutupan lahan (Land use land cover change) Kawasan Rinjani, Lombok". Mataram: WWF Nusa Tenggara.

\section{Profil Penulis}

I Komang Deya Pradnyana, S.Par. Penulis menyelesaikan program Sarjana (S1) Pada Program Studi Industri Perjalanan Wisata Univeritas Udayana pada tahun 2016. Saat ini penulis sedang menyelesaikan Program Studi Magister Pariwisata Universitas Udayana tahun 2021.

Ir. Anak Agung Putu Agung Suryawan Wiranatha, Msc., Ph.D adalah dosen pada Program Studi Magister Pariwisata yang menyelesaikan pendidikan S1 di Institut Pertanian Bogor, S2 di Griffith University, Australia dan S3 di The University of Queensland, Australia. Bidang keahlian yang ditekuni adalah Perencanaan dan Pengembangan Pariwisata, Pariwisata Berkelanjutan dan Permodelan Sistem Pariwisata.

Dr. Ir. I Gusti Ayu Oka Suryawardani, M.Mgt., Ph.D merupakan Dosen yang saat ini menjabat sebagai Ketua Program Studi Magister Pariwisata yang menyelesaikan pendidikan S1 di Fakultas Pertanian Universitas Udayana, S2 di Faculty of Economic Business and Law, The University of Queensland, Brisbane Autsralia dan S3 Double Degree Indonesia Prancis: Unud - Paris 1 Pantheon Sorbonne, Paris, France. Bidang keahlian yang ditekuni adalah Tourism Economics, Tourism Marketing dan Permodelan Sistem Pariwisata. 